\title{
Effects of Nutrients Supplementation on Enhanced Biogas Production from Maize Silage and Cattle Slurry Mixture
}

\author{
Marcin Zieliński • Marta Kisielewska (D) \\ Marcin Dębowski • Katarzyna Elbruda
}

Received: 11 January 2019 /Accepted: 18 April 2019/Published online: 11 May 2019

(C) The Author(s) 2019

\begin{abstract}
This study investigated the effects of nutrients supplementation during codigestion of maize silage and cattle slurry. Batch anaerobic biodegradability tests lasted 20 days under mesophilic conditions, and an organic loading rate of $5.0 \mathrm{~g}$ VS (volatile solids)/L were done. Biogas yield increased with the dose of the cattle feed supplement up to $894 \mathrm{~L} / \mathrm{kg} \mathrm{VS}$, which was $65 \%$ higher than in the control reactor. Similarly, the cumulative biogas production rate (CBPR) increased with successive increase in the dose of feed supplement. Supplementation enabled efficient volatile fatty acids (VFA) elimination and $\mathrm{pH}$ increasing; however, the best VFA/TA ratio was achieved with feed supplementation of $25 \mathrm{mg} / \mathrm{g}$ of feedstock, providing the highest rate of biogas production $(k=0.22 / \mathrm{d})$. The highest increase in biogas production of $8.0 \mathrm{~mL} / \mathrm{mg}$ was achieved with the lowest nutrient supplement dosage. Based on these results, it can be recommended that a supply of feed supplement at a ratio of $0.5 \%$ of the fresh mass provide considerably increasing biogas production.
\end{abstract}

Keywords Nutrients supplement · Additives . Anaerobic digestion $\cdot$ Agricultural residues $\cdot$ Renewable energy

M. Zieliński • M. Kisielewska $(\bowtie) \cdot$ M. Dębowski •

K. Elbruda

Department of Environmental Engineering, University of Warmia and Mazury in Olsztyn, Warszawska Str. 117A, 10-720 Olsztyn, Poland

e-mail: jedrzejewska@uwm.edu.pl

\section{Introduction}

A global trend for biofuels production is focused on sustainability in environmental and economic aspects. To meet the acceptable sustainability criteria, the second generation biofuel technologies manufacture biofuels from non-food biomass. Agricultural residues available for the second generation biofuels include various crop and plant residues, fruit and vegetable waste, grass, forest residues, livestock manure, and many other byproducts of various agricultural processes (Paudel et al. 2017). The anaerobic digestion (AD) of agricultural residues is an attractive second-generation technology with the potential of environmental and economic benefits (Wei et al. 2015).

$\mathrm{AD}$ is now a well-established treatment technology suited for wastewater or wastes containing high levels of organic matter. Biogas produced during $\mathrm{AD}$ is a renewable energy source that can replace conventional fuels to produce heat, power, and it can also be used as gaseous fuel in automotive applications (Achinas et al. 2017). Energy gain/input ratio in $\mathrm{AD}$ is estimated at $28.8 \mathrm{MJ} /$ MJ, which outcompetes the other technologies for bioenergy production from biomass (Chandra et al. 2012a, b). Biogas calorific value is determined by the methane concentration, which is affected by many operational parameters, i.e., temperature, $\mathrm{pH}$, mixing, and humidity (Yebo et al. 2011). However, the most significant factor governing the biogas yield and composition is a feedstock characteristic. Well-balanced feedstock should ensure highly efficient biogas production. There are many studies concerning the impact of pretreatments 
methods and codigestion strategies on biogas production from agricultural residues (Zheng et al. 2014; Wei et al. 2015), while less attention has been paid to inorganic nutrients supplementation for AD stimulation.

Mineral nutrients play an important role as the growing factors supporting the microorganisms' metabolism to maintain the effective digestion process (Sibiya et al. 2015; Choong et al. 2016). Methanogens are highly dependent on micronutrients such as $\mathrm{Fe}, \mathrm{Zn}, \mathrm{Ni}, \mathrm{Cu}$, $\mathrm{Co}, \mathrm{Mn}$, which stimulate reactions catalyzed by metalloenzymes, formation of cytochromes, and ferroxins (Moestedt et al. 2016; Bougrier et al. 2018). Macronutrients $(\mathrm{C}, \mathrm{N}, \mathrm{S}, \mathrm{P}, \mathrm{H})$ also play an important role in the growth and metabolism of anaerobic microorganisms acting as buffering agents and enzyme components (Pobeheim et al. 2010; Takashima et al. 2011). However, the presence of nutrients in the feedstock not always guarantee that $\mathrm{AD}$ is efficient because the process can only be carried out successfully with the certain nutrients concentrations (Sibiya et al. 2015; Bougrier et al. 2018). The nutrients requirements of the mixed methanogens culture are not now well understood and may vary depending on the feedstock characteristics as well as the involved species and their methanogenic pathways (Ortner et al. 2015; Choong et al. 2016). Thus, there is a great challenge to clarified a suitable dose of nutrients to improve the performance of methane production from agricultural residues. The objective of the study was the impact of different levels of nutrient supplementation on biogas yield from cattle slurry and maize silage mixture.

\section{Materials and Methods}

\subsection{Feedstock Origin and Characteristics}

In this study, cattle slurry and maize silage mixture were used as a substrate for AD. Cattle slurry and maize silage were obtained from a farm located at the Research Station of University of Warmia and Mazury in Olsztyn in Bałdy (Poland). The cattle slurry was collected directly from the temporary field storage of solid manure All samples were collected at five locations, each in amount of $1 \mathrm{~kg}$. Then, the $5 \mathrm{~kg}$ sample was stirred to ensure the homogeneity. Maize silage was collected in the same manner. Cattle slurry and maize silage used as a feedstock for $\mathrm{AD}$ were mixed in weight based ratio of $1: 4$. Then, $250 \mathrm{~g}$ of a mixed sample was homogenized for $20 \mathrm{~min}$. (Robo 30, Germany) to obtain a homogeneous mixture. Then the sample was hydrated with fresh water to the average total solids (TS) value of $25.4 \%$ and volatile solids (VS) value of $79 \%$ TS.

\subsection{Feed Supplement Source}

Typical feed supplement for dairy cattle was used as a nutrient source for AD of the mixture of cattle slurry and maize silage. The nutrient source contained the following: crude fiber $5.6 \%$, crude oils and fats $3.7 \%$, organic phosphorus $0.67 \%$, magnesium $0.5 \%$, crude protein $17.9 \%$, crude ash $7.1 \%$, calcium $0.7 \%$, sodium $0.35 \%$, zinc oxide $76 \mathrm{mg} / \mathrm{kg}$, vitamin E $30 \mathrm{mg} / \mathrm{kg}$, sodium selenate $0.6 \mathrm{mg} / \mathrm{kg}$, calcium iodate $2 \mathrm{mg} / \mathrm{kg}$, magnesium oxide $61 \mathrm{mg} / \mathrm{kg}$, copper sulphate $5 \mathrm{H}_{2} \mathrm{O} 30 \mathrm{mg} / \mathrm{kg}$, and ferrous sulphate monohydrate $25 \mathrm{mg} / \mathrm{kg}$. Cattle feed supplement was added to the anaerobic reactors in different doses showed in Table 1 . The study was performed in six experimental variants differed in the amount of feed supplement used.

\subsection{Batch Anaerobic Biodegradability Tests}

AD of agricultural residues with nutrient supplementation was conducted using Oxi-Top® respirometers (WTW, USA) that consisted of the bottles with an active volume of $1 \mathrm{~L}$ coupled tightly with measuring devices recorded an increase of the partial pressure induced by biogas production. Pressure in the reaction tank was recorded every $80 \mathrm{~min}$. The perfect gas equation was the basis for computing the volume of produced biogas in respirometric tests. The volumes of biogas generated per normal conditions were computed on the basis of

Table 1 The study organization

\begin{tabular}{llll}
\hline Variants & $\begin{array}{l}\text { mg/mL mass of } \\
\text { feed supplement } \\
\text { per unit volume } \\
\text { of a reaction tank }\end{array}$ & $\begin{array}{l}\text { mg/g mass of } \\
\text { feed supplement } \\
\text { per fresh mass of } \\
\text { the feedstock }\end{array}$ & $\begin{array}{l}\text { mg/g mass of } \\
\text { feed supplement } \\
\text { per organic dry } \\
\text { mass of the } \\
\text { feedstock }\end{array}$ \\
\hline B & 0 & 0 & 0 \\
G1 & 0.1 & 5 & 19 \\
G2 & 0.2 & 10 & 39 \\
G3 & 0.5 & 25 & 97 \\
G4 & 1 & 50 & 193 \\
G5 & 2 & 100 & 387 \\
\hline
\end{tabular}


pressure changes inside the bottle headspace. Respirometric tests also provided grounds to determine the biogas production rates. The endogenous production of the anaerobic sludge was removed from the calculations of biogas and methane productions of the tests. Similarly, the biogas production from the raw feed supplement source was measured and subtracted from the measured gas production. Anaerobic sludge for inoculation originated from the closed postfermentation tanks of agriculture biogas plant with TS concentration of 3.7 $\pm 0.3 \%$ and VS concentration of $69.2 \pm 2.8 \%$. In order to ensure anaerobic conditions inside the respirometers, nitrogen gas was injected into each bottle for $5 \mathrm{~min}$ to remove atmospheric air. The experiments were carried out at a constant mesophilic condition $\left(36{ }^{\circ} \mathrm{C}\right)$ in a shaking incubator at $150 \mathrm{rpm}$. Respirometers with a size of $1 \mathrm{~L}$ were filled with $50 \mathrm{~mL}$ of anaerobic sludge and a mixture of feedstock and cattle feed supplement to achieve initial organic loading rate (OLR) of $5.0 \mathrm{~g} \mathrm{VS} /$ $\mathrm{L}$ in all tested variants. Biodegradability tests were carried out for a period of 20 days.

\subsection{Analytical Methods}

The gravimetric method was used to determine TS and VS in samples of homogenized mixture of maize silage and cattle slurry. The composition of biogas produced in the headspace of respirometers was measured every $24 \mathrm{~h}$ using a portable gas analyzer GMF (gas data). The percentage volumes of $\mathrm{CH}_{4}(\% v / v), \mathrm{CO}_{2}(\% v / v), \mathrm{O}_{2}$
$(\% v / v), \mathrm{H}_{2} \mathrm{~S}$ (ppm), $\mathrm{H}_{2}$ (ppm), $\mathrm{NH}_{4}$ (ppm) were determined. The tritation method (Tritlab AT 1000, Hach) was used for the determination of VFA/TA ratio (volatile fatty acids and total alkalinity ratio). The $\mathrm{pH}$ value was determined by HQ 440d digital pH-meter (Hach).

Based on the pressure measurement results in respirometers, the kinetics of biogas production were determined depending on the amount of cattle feed supplement. The reaction rate constants were determined based on the measurement data using the nonlinear regression method and an iterative method. In the method at each iterative step, the function is replaced with the linear differential for the designated parameters. As a test of the curve fit (for the designated parameters) to the experimental data, the $\varphi^{2}$ coefficient of concordance was applied. The coefficient is the ratio of the sum of the squares of the deviations from the values calculated, using the found function, from the experimental data, to the sum of the squares of the deviations of the experimental data from the mean. The lower the $\varphi^{2}$ coefficient value, the better the concordance.

Each experimental variant was conducted in three replications. The results were statistically analyzed with Statistica 10.0 PL package (Statsoft, Inc.). The hypothesis on distribution of each analyzed variable was verified with a Shapiro-Wilk $W$ test. One-way analysis of variance (ANOVA) was applied to determine the significance of difference between variables. Variance homogeneity in groups was checked with a Levene test, whereas the significance of
Fig. 1 Specific biogas yield (SBY) with different amount of cattle feed supplement

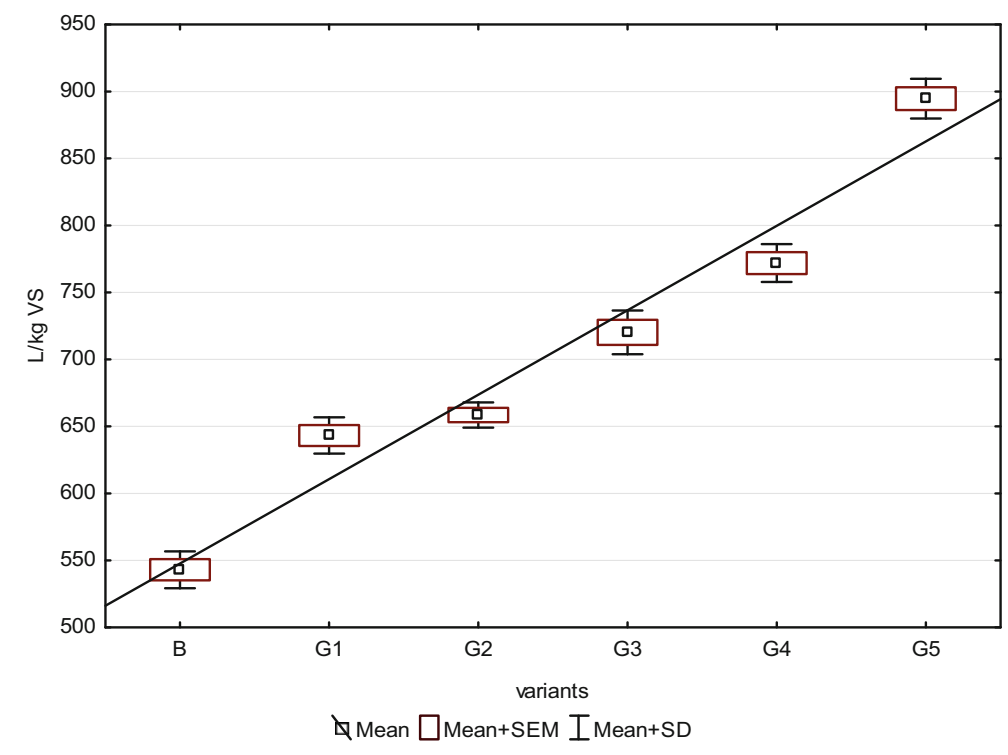


differences between the analyzed variables was determined with a Tukey RIR test. In all tests, the level of significance was adopted at $p=0.05$.

\section{Results and Discussion}

Bioreactors are designed to control and enhance specific biochemical reactions and many of them taking place in nature. $\mathrm{AD}$ bioprocess reproduces rumen fermentation, where acidification, hydrolysis, and then acidogenesis and methanogenesis occur. However, the rates of biodegradation occurring in the anaerobic bioreactors still remain lower than in animal guts (Bayané and Guiot 2011). Moreover, digestion in the animal ruminants can be additionally enhanced by feed additives, which stimulate the rumen functions. In our study, feed supplement for dairy cattle was successfully used as a nutrient
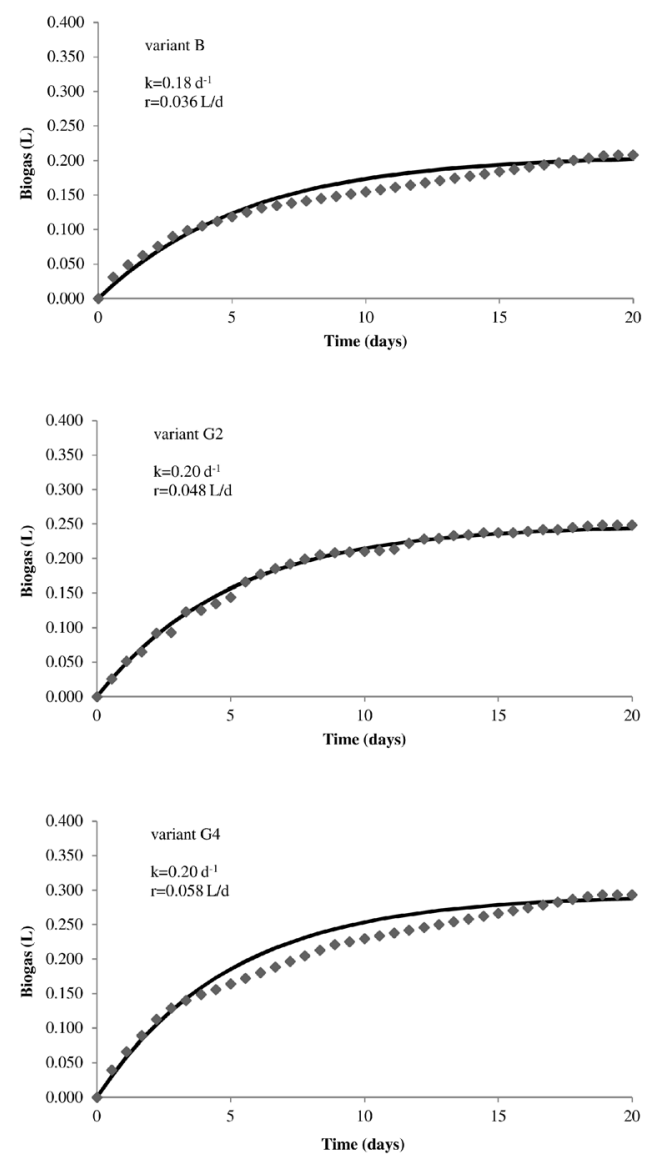

medium for microorganisms in methanogenic $\mathrm{AD}$ of maize silage and cattle slurry mixture.

\subsection{Biogas Yields and Kinetics}

Figure 1 shows the specific biogas yield (SBY) in all tested variants compared to the control variant without nutrients supplementation. It was found that SBY increased with increasing dose of cattle feed supplement from $643 \mathrm{~L} / \mathrm{kg}$ VS in G1 to $894 \mathrm{~L} / \mathrm{kg}$ VS in G5. Similarly, the cumulative biogas production rate (CBPR) increased with successive increase in the dose of cattle feed supplement (Fig. 2). Interestingly, even $19 \mathrm{mg}$ of feed supplement per $1 \mathrm{~g}$ VS of the feedstock (G1 variant) resulted in significant increase in biogas production compared with the control variant (B) $(p<0.05)$. In the control variant (B), SBY achieved $543 \mathrm{~L} / \mathrm{kg}$ VS, which was around the values reported in the literature. Typical
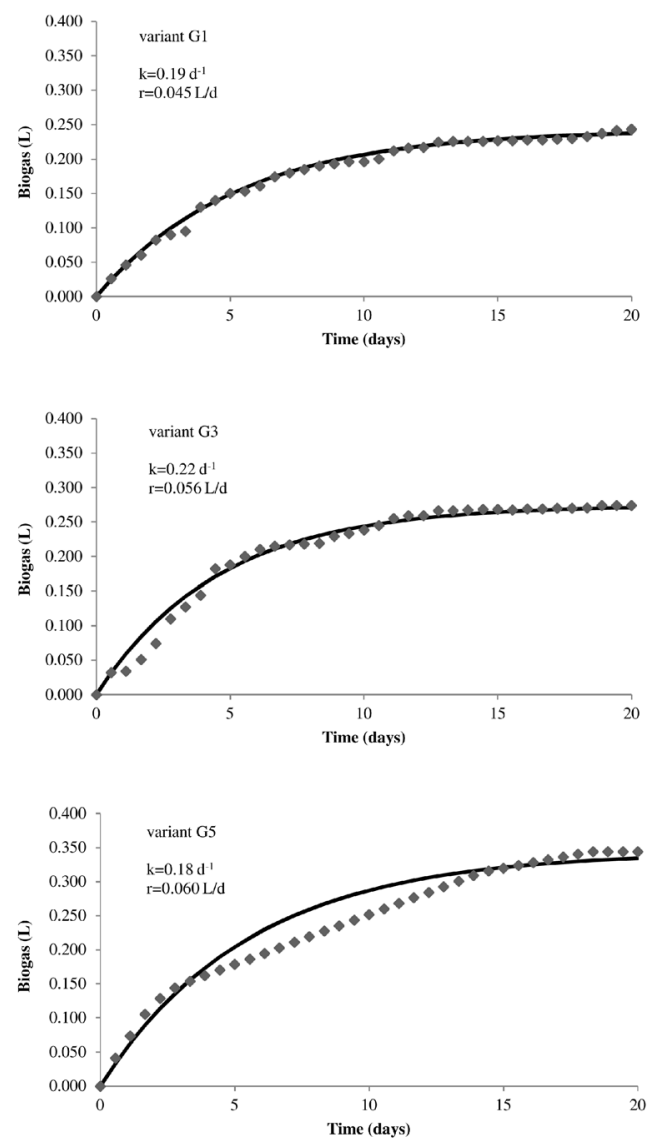

Fig. 2 Cumulative biogas production rate (CBPR) using different amount of cattle feed supplement 
biogas yield for maize ranged from 560 to $650 \mathrm{~L} / \mathrm{kg} \mathrm{VS}$ (Weiland 2010), while cattle manure had a biogas yield of 200-300 L/kg VS (Nasir et al. 2012). El-Mashad and Zhang (2010) achieved SBY of 406 L/kg VS from dairy manure and about $500 \mathrm{~L} / \mathrm{kg}$ VS from the mixture of dairy manure $(52 \%)$ with food waste $(45 \%$ based on VS) after 20 days of AD.

It was found that strategy of nutrients supplementation was highly recommended for the digestion substrates which originally have low trace element contents such as food wastes and energy crops (Nges et al. 2012; Choong et al. 2016). Nordell et al. (2016) found, that trace element supplementation enhanced codigestion of manure from swine and dairy animals with municipal solid waste. SBY achieved nearly $1000 \mathrm{~L} / \mathrm{kg}$ VS when the trace element solution was added to the continuously stirred tank reactor (CSTR), while it was about $900 \mathrm{~L} / \mathrm{kg}$ VS in CSTR without nutrient supplementation. The supplementation of $\mathrm{Fe}, \mathrm{Co}$, Mo, and $\mathrm{Ni}$ to anaerobic batch reactors treated food waste allowed to obtain the specific methane yield of $504 \mathrm{~mL} / \mathrm{g} \mathrm{VS}$, which was $35.5 \%$ higher compared with reactors without metals supplementation (Zhang et al. 2015).

Administration of nutrient supplementation dosage is now one of the most promising way of optimizing AD (Moestedt et al. 2016). An optimally adjusted trace element supplementation provides the stabilization and optimization of $\mathrm{AD}$ by promoting the growth of microorganisms involved in the process and allowing the accumulation of the necessary enzymes and coenzymes balance (Zhang et al. 2015). According to the results of the study, the biogas production per $1 \mathrm{mg}$ of the introduced cattle feed supplement was inversely proportional (Fig. 3). The highest increase in biogas production of $8.0 \mathrm{~mL} / \mathrm{mg}$ was achieved with the lowest nutrient supplement dosage. It should be noted that nutrient addition should be always optimized to balance the economic costs of high performance of AD. There was no relationship between the amount of nutrient supplementation and the methane content in biogas. In all experimental variants, the concentration of methane ranged from 52 to $54 \%(p>0.05)$. According to literature, methane content in biogas is connected mainly with the composition of the feedstock, and it increases with the increasing fat and protein contents (Chandra et al. 2012a). Thus, the similar biogas content in all experimental variants was the result of the unchanging composition of the feedstock.

\subsection{Liquid Phase Parameters}

The balance between the processes of hydrolysis, acidogenesis, acetogenesis, and methanogenesis are crucial to reach successful in biogas yield and organic

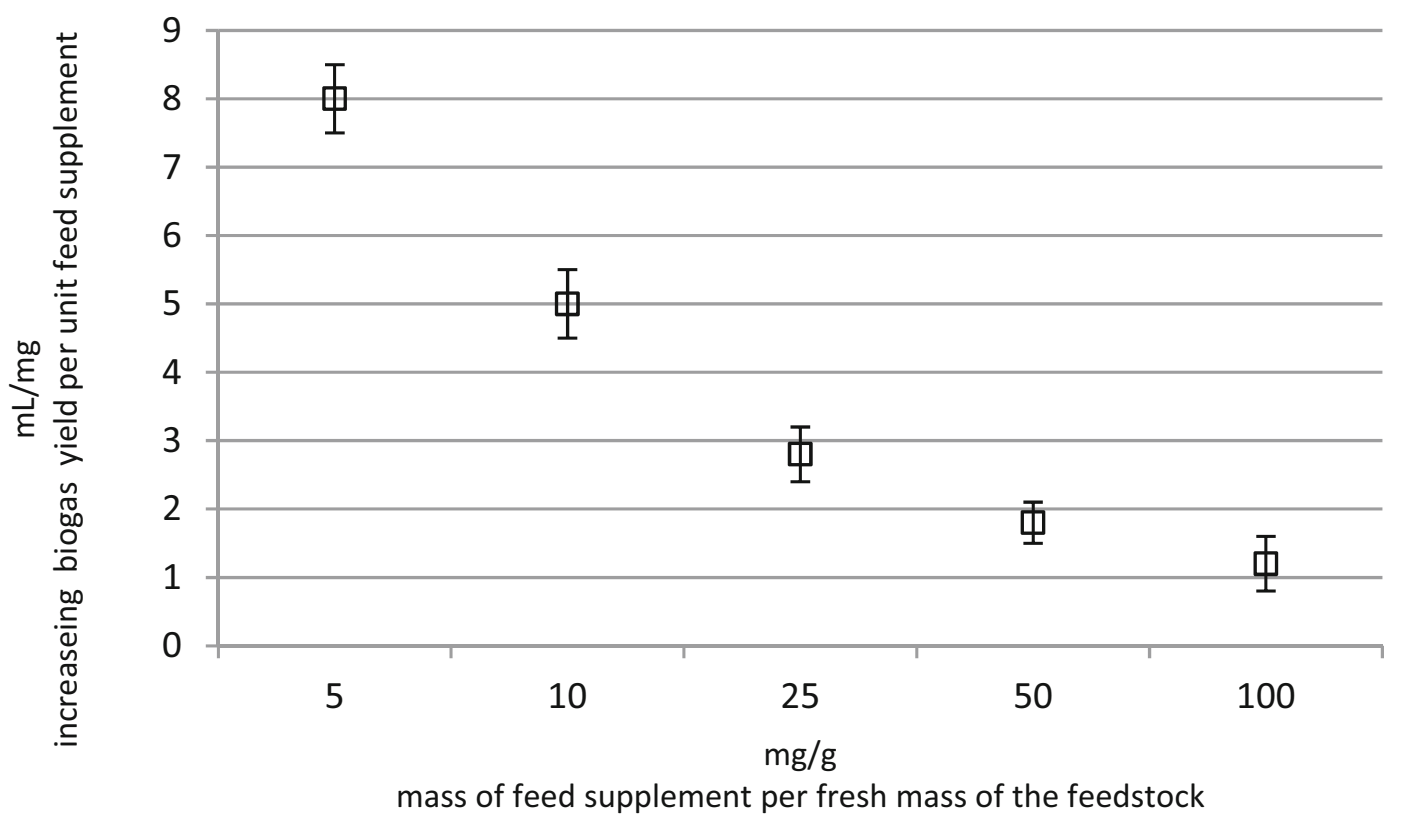

Fig. 3 Increase biogas yield per unit cattle feed supplement $(\mathrm{mL} / \mathrm{g})$ 
matter biodegradation. Excessive production of VFA during hydrolysis and acetogenesis phase can cause inhibition in methanogens metabolism (Lee et al. 2014). In this study, stability of AD was evaluated based on the evolution of VFA, VFA/TA ratio, and $\mathrm{pH}$ in the liquid phase after 20 days of the digestion (Table 2).

Nutrients supplementation during AD of maize silage and cattle slurry mixture was effective in enhancing VFA elimination and $\mathrm{pH}$ increasing. The concentration of VFA was the highest in the control variant (B) and showed a decreasing trend with increasing dose of cattle feed supplement (Table 2). Even the lowest supplementation of nutrients reduced VFA concentration by half compared with the control variant. At the same time, $\mathrm{pH}$ was the lowest in variant $\mathrm{B}$, and subsequent addition of cattle feed supplement ensured an increase in $\mathrm{pH}$ (Table 2). However, in all variants of experiment $\mathrm{pH}$ remained optimal for methanogens.

A ratio of VFA/TA in variants with supplementation balanced between 0.28 and 0.18 , reaching in $\mathrm{G} 2$ and $\mathrm{G} 3$, a value very close to 0.25 , which is an ideal value according to the scientific literature (Rosato 2017). Considering biogas production rate related to VFA/TA ratio, the highest rate of biogas production $(k=0.22 / \mathrm{d})$ was obtained in G3 variant.

Agricultural residues such as maize and grass are characterized by the lack of essential nutrients, thus $\mathrm{AD}$ of these substrates resulted in low methane yield, acidification problems, and instability of the whole process (Weiland 2010; Nges et al. 2012; Sibiya et al. 2015). Codigesting energy crops with manure is a strategy used in many crop-based biogas plants in Germany to enhance biogas production; however, substrate biodegradability limitation is observed even on a prolonged HRT (Nges et al. 2012). Supplementation of nutrients allowed VFA degradation at a high rate, which ensures obtaining the optimum $\mathrm{pH}$ level (6.5-7.5) for

Table 2 Liquid phase parameters

\begin{tabular}{llrl}
\hline Variants & $\mathrm{pH}$ & $\mathrm{VFA} \mathrm{mg} / \mathrm{L}$ & \multicolumn{1}{l}{ VFA/TA } \\
\hline B & $6.93( \pm 0.11)$ & $2450( \pm 320)$ & $0.39( \pm 0.05)$ \\
G1 & $7.21( \pm 0.08)$ & $1290( \pm 280)$ & $0.28( \pm 0.06)$ \\
G2 & $7.29( \pm 0.07)$ & $970( \pm 190)$ & $0.27( \pm 0.05)$ \\
G3 & $7.32( \pm 0.10)$ & $840( \pm 270)$ & $0.24( \pm 0.08)$ \\
G4 & $7.39( \pm 0.09)$ & $560( \pm 120)$ & $0.23( \pm 0.05)$ \\
G5 & $7.48( \pm 0.12)$ & $440( \pm 160)$ & $0.18( \pm 0.06)$ \\
\hline
\end{tabular}

maintaining the ideal living surroundings of microbes and stability of the digester (Nges et al. 2012; Zhang et al. 2015; Choong et al. 2016). The study showed that typical feed supplement for dairy cattle may be effectively used to intensify the biogas production from agricultural residues.

\section{Conclusions}

Our study demonstrated that the strategy of nutrients supplementation during AD of maize silage and cattle slurry mixture is beneficial. This was evidenced by good biogas yield, high $\mathrm{pH}$, low VFA concentrations, and the improvement of VFA/TA ratio. The specific biogas yield SBY increased with the increasing dose of cattle feed supplement from $543 \mathrm{~L} / \mathrm{kg}$ VS in the control variant to the maximum value of $894 \mathrm{~L} / \mathrm{kg}$ VS. Nutrient supplementation did not enhance the methane content in biogas, which ranged from 52 to $54 \%(p>0.05)$. However, an optimal dose of supplement is crucial in order to have a successful $\mathrm{AD}$ and low costs of the process. In our study, nutrient supplementation of $0.5 \%$ of the fresh mass considerably increased biogas production.

Acknowledgements This work was supported by University of Warmia and Mazury in Olsztyn project No. 18.610.008-300.

Open Access This article is distributed under the terms of the Creative Commons Attribution 4.0 International License (http:// creativecommons.org/licenses/by/4.0/), which permits unrestricted use, distribution, and reproduction in any medium, provided you give appropriate credit to the original author(s) and the source, provide a link to the Creative Commons license, and indicate if changes were made.

\section{References}

Achinas, S., Achinas, V., Jan, G., \& Euverink, W. (2017). A technological overview of biogas production from biowaste. Engineering, 3(3), 299-307.

Bayané, A., \& Guiot, S. R. (2011). Animal digestive strategies versus anaerobic digestion bioprocesses for biogas production from lignocellulosic biomass. Reviews in Environmental Science and Bio/Technology, 10, 43-62.

Bougrier, C., Dognin, D., Laroche, C., Gonzalez, V., BenaliRaclot, D., \& Cacho Rivero, J. A. (2018). Anaerobic digestion of brewery spent grains: trace elements addition requirement. Bioresource Technology, 247, 1193-1196.

Chandra, R., Takeuchi, H., \& Hasegawa, T. (2012a). Methane production from lignocellulosic agricultural crop wastes: a 
review in context to second generation of biofuel production. Renewable and Sustainable Energy Reviews, 16, 1462-1476.

Chandra, R., Takeuchi, H., \& Hasegawa, T. (2012b). Improving biodegradability and biogas production of wheat straw substrates using sodium hydroxide and hydrothermal pretreatments. Energy, 43, 273-282.

Choong, Y. Y., Norli, I., Abdullah, A. Z., \& Yhaya, M. F. (2016). Impacts of trace element supplementation on the performance of anaerobic digestion process: a critical review. Bioresource Technology, 209, 369-379.

El-Mashad, H. M., \& Zhang, R. (2010). Biogas production from co-digestion of dairy manure and food waste. Bioresource Technology, 101(11), 4021-4028.

Lee, W. S., Chua, A. S. M., Yeoh, H. K., \& Ngoh, G. C. (2014). A review of the production and applications of waste-derived volatile fatty acids. Chemical Engineering Journal, l235, 8399.

Moestedt, J., Nordell, E., Shakeri Yekta, S., Lundgren, J., Martí, M., Sundberg, C., Ejlertsson, J., Svensson, B. H., \& Björn, A. (2016). Effects of trace element addition on process stability during anaerobic co-digestion of OFMSW and slaughterhouse waste. Waste Management, 47, Part A, 11-20.

Nasir, I. M., Mohd Ghazi, T. I., \& Omar, R. (2012). Anaerobic digestion technology in livestock manure treatment for biogas production: a review. Engineering in Life Science, 12, 258-269.

Nges, I. A., Björn, A., \& Björnsson, L. (2012). Stable operation during pilot-scale anaerobic digestion of nutrientsupplemented maize/sugar beet silage. Bioresource Technology, 118, 445-454.

Nordell, E., Nilsson, B., Påledal, S. N., Karisalmi, K., \& Moestedt, J. (2016). Co-digestion of manure and industrial waste - the effects of trace element addition. Waste Management, 47(part A), 21-27.

Ortner, M., Rameder, M., Rachbauer, L., Bochmann, G., \& Fuchs, W. (2015). Bioavailability of essential trace elements and their impact on anaerobic digestion of slaughterhouse waste. Biochemical Engineering Journal, 99, 107-113.

Paudel, S. R., Banjara, S. P., Choi, O. K., Park, K. Y., Kim, Y. M., \& Lee, J. W. (2017). Pretreatment of agricultural biomass for anaerobic digestion: current state and challenges - review. Bioresource Technology, 245, 1194-1205.
Pobeheim, H., Munk, B., Johansson, J., \& Guebitz, G. M. (2010). Influence of trace elements on methane formation from a synthetic model substrate for maize silage. Bioresource Technology, 101, 836-839.

Rosato, M. A. (2017). Managing biogas plants - a practical guide. Florida: CRP Press Taylor \& Francis Group.

Sibiya, N.T., Tesfagiorgis, H.B., Muzenda, E. (2015). Influence of nutrients addition for enhanced biogas production from energy crops: a review. 7th International Conference on Latest Trends in Engineering \& Technology (ICLTET'2015) Nov. 26-27, 2015, Irene, Pretoria (South Africa). http://iieng.org/images/proceedings_pdf/4554E1115038.pdf

Takashima, M., Shimada, K., \& Speece, R. E. (2011). Minimum requirements for trace metals (iron, nickel, cobalt, and zinc) in thermophilic and mesophilic methane fermentation from glucose. Water Environment Research, 83(4), 339-346.

Wei, Y., Li, X., Yu, L., Zou, D., \& Yuan, H. (2015). Mesophilic anaerobic co-digestion of cattle manure and corn Stover with biological and chemical pretreatment. Bioresource Technology, 198, 431-436.

Weiland, P. (2010). Biogas production: current state and perspectives. Applied Microbiology and Biotechnology, 85(4), 849860.

Yebo, L., Park, S., \& Zhu, J. (2011). Solid-state anaerobic digestion for methane production from organic waste. Renewable and Sustainable Energy Review, 15, 821-826.

Zhang, W., Zhang, L., \& Li, A. (2015). Enhanced anaerobic digestion of food waste by trace metal elements supplementation and reduced metals dosage by green chelating agent $[\mathrm{S}$, S]-EDDS via improving metals bioavailability. Water Research, 84, 266-277.

Zheng, Y., Zhao, J., Xu, F., \& Li, Y. (2014). Pretreatment of lignocellulosic biomass for enhanced biogas production. Progress in Energy and Combustion Science, 42, 35-53.

Publisher's Note Springer Nature remains neutral with regard to jurisdictional claims in published maps and institutional affiliations. 